\title{
STUDIES CONCERNING FUNCTIONAL DIFFERENCES BETWEEN LIVER REGIONS SUPPLIED BY THE HEPATIC ARTERY AND BY THE PORTAL VEIN *
}

\author{
By RALPH W. BRAUER, OTTO S. SHILL AND JOHN S. KREBS \\ (From the United States Naval Radiological Defense Laboratory, San Francisco, Calif.)
}

(Submitted for publication May 11, 1959; accepted August 20, 1959)

The small bile ducts in the liver of a number of species are enmeshed by a vascular plexus, supplied largely by the hepatic artery' (1-3). This peribiliary arterial plexus has been considered by some as evidence that the bile duct epithelia might play an important and active role in the secretion of bile, possibly even to the exclusion of the parenchymal cells $(4,5)$. In support of this view, it was reported that in the dog the dye sulfobromophthalein sodium (BSP) is removed more completely, and for longer periods of time, when infused into the hepatic artery than when it reaches the liver by way of the portal vein. Since the vascular pathways traversed are common for both routes of injection, except for the intercalation of the peribiliary plexus in the path of part of the arterial blood, this was the site where the extra BSP uptake was thought to take place (6). By way of interpretation the possibility was suggested that BSP is preferentially excreted into bile when taken up by the tissues supplied by this plexus, i.e., by the smaller bile ducts.

No direct test of this hypothesis was undertaken, however. With the availability of $\mathrm{S}^{35}$-labeled BSP (7) the possibility suggested itself of using this material in conjunction with nonradioactive BSP to trace quantitatively two simultaneous BSP injections from two injection sites-portal vein and hepatic artery, for example-into bile, and thus to subject the concept of preferential biliary excretion of intra-arterially administered BSP to a critical test.

To validate the results of any such experiments requires some further analysis of the qualitative pattern of BSP excretion into bile and of the degree to which this might vary with the route by which the dye reaches the liver, as well as of the

\footnotetext{
* The opinions and assertions contained in this report are the private ones of the writers and are not to be construed as official or reflecting the views of the Navy Department or the Naval Service at large.
}

efficiency with which the dye is removed from arterial and from portal venous blood by the liver in vivo.

The present communication will deal with each of these subjects in turn, presenting validating bile secretion studies first, then the simultaneous injection experiments, and finally the extraction efficiency measurements and related studies dealing with the problem of obtaining representative hepatic vein samples.

\section{METHODS}

The experiments were carried out on female mongrel dogs, 9.5 to $15.0 \mathrm{Kg}$., which had been maintained in the laboratory on commercial canned dog food for at least six weeks. They were free of acute disease, and histopathological examination showed the livers of all animals used in these experiments to be free of significant abnormalities. Intravenous sodium pentobarbital anesthesia was employed throughout, respiratory rates being maintained between 14 and 20 per minute. Rectal temperatures were maintained above $35.5^{\circ} \mathrm{C}$., if necessary, by the use of hot pads; in any one animal rectal temperature fluctuations did not exceed a range of $2.5^{\circ} \mathrm{C}$.

Injections were made through polyethylene catheters, ending in 24 gage needles which were inserted into the gastrohepatic artery, 3 to $5 \mathrm{~cm}$. proximal to the branchingoff of the hilar hepatic arteries, and also into the portal vein, either just cephalad of the confluence of common intestinal and mesenteric veins, or at the junction of portal and gastrosplenic veins. These catheters were inserted at laparotomy, and brought to the body surface through the incision wound which was then closed by a single line of sutures. Catheter positions were rechecked at autopsy after the completion of each experiment. The possibility that dye injected via the hepatic artery might not reach the liver directly but be partially washed into the right gastric branches of the gastrohepatic artery was eliminated by careful placing of the arterial catheter and by an open loop placed around the gastric branch and tightened for ten seconds during and after the injections.

Blood samples were obtained from the femoral artery by direct puncture, and from the portal vein $3 \mathrm{~cm}$. cephalad of the injection site through an additional polyethylene catheter. In addition, radiopaque catheters 


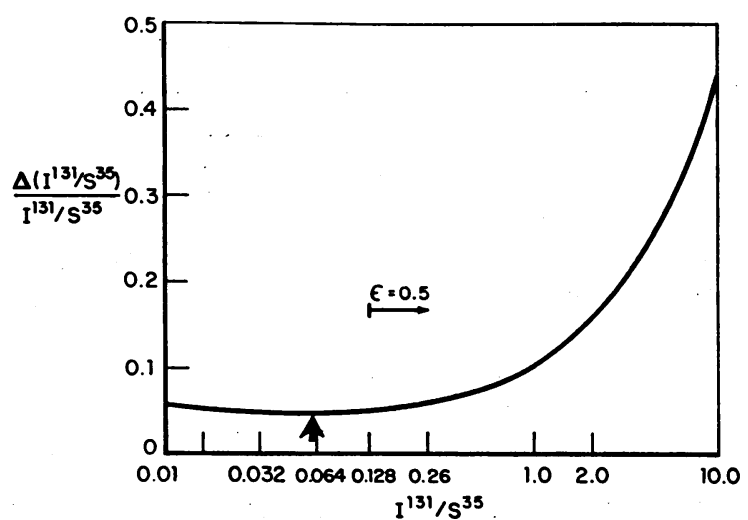

Fig. 1. ERror in I Im/ $/ \mathrm{S}^{26}$ Ratio Due to Constant Counting ERror ( \pm 3 per cent), as a Function of $\mathrm{I}^{121} / \mathrm{S}^{25}$

The interval marked $\epsilon=0.5$ represents the interval covered by a typical experiment in which 50 per cent of the injected $S^{35}$ BSP was removed from the blood in one passage through the liver.

were guided fluoroscopically to the following positions: a) vena cava, the tip being placed either $5 \mathrm{~cm}$. cephalad, or $3 \mathrm{~cm}$. caudad of its entry into the thorax above the dome of the diaphragm; $b$ ) hepatic vein, either one sampling catheter with its collecting tip $2 \mathrm{~cm}$. cephalad of the point of wedging either in the right lateral lobe only, or two catheters with their tips placed in analagous positions in two hepatic veins in different lobes. $\mathrm{Ca}$ theter sizes used were No. 10 in the vena cava, and No. 6 or (in the majority of experiments) No. 8 in the hepatic vein.

Blood samples from these catheters were withdrawn using a spring return plunger type of syringe equipped with directional ball valves (B-D Cornwall Pipetting Unit). This allowed collection of numerous $0.5 \mathrm{ml}$. samples at a rate of up to one sample per second from each catheter. The total dead space of each catheter together with its collection assembly was determined and found to be less than $1.5 \mathrm{ml}$. in every case. Mixing of samples in the system was negligible as shown by the sample concentration curves obtained on abruptly transferring the catheters from one to another solution of different composition, analyzing the catheter samples, and correcting for dead space lag.

Bile was collected into graduated centrifuge tubes from a plastic catheter inserted into the common bile duct after cholecystectomy. This catheter was placed at the same time as the injection catheters, brought out through the laparotomy wound, and placed so that the catheter opened into the collecting tubes at a level 2 $\mathrm{cm}$. above the common duct.

Sodium phenoltetrabromphthalein disulfonate (BSP) was labeled with $\mathrm{S}^{25}$ in the sulfonic acid groups (7)..$^{1}$

1 The authors are indebted to Dr. H. Brown Dunning, Jr., of Hynson, Westcott and Dunning, Inc., for making available the phenoltetrabromphthalein used in the synthesis of the labeled dye.
Colorimetric analyses for BSP in bile and blood plasma were carried out at $580 \mathrm{~m} \mu$. using the sample preparation and standardization methods previously described (8). $\mathrm{S}^{26}$ content was determined using air dried samples plated on tissue paper covered planchets in essentially infinite layer geometry in conjunction with a thin endwindow Geiger-Müller detector. Standardization against known amounts of $\mathrm{S}^{26} \mathrm{BSP}$ added to isotope-free samples of blood or bile, and details of the counting procedure have been reported elsewhere (8). All BSP analyses are recorded as milligrams of injected BSP equivalent to the optical density at $580 \mathrm{~m} \mu$.. or to the amount of $\mathrm{S}^{26}$ detected in $1 \mathrm{ml}$. of sample.

$\mathrm{P}^{32}$-labeled chromic phosphate colloid, ${ }^{2}$ prepared according to the method of Dobson and Jones (9), was handled for injection or analysis using the precautions described by Brauer, Leong, McElroy and Holloway (10) ; blood radioactivity due to this substance was determined on air dried planchets, using an end-window Geiger-Müller counter and is expressed as percentage of injected dose per milliliter of sample.

Im-labeled human serum albumin (IHSA), free of dialyzable radioactivity, was diluted for injection and analysis so that total protein concentrations did not fall below 1 per cent at any time. In these experiments IHSA was employed in combination with $\mathrm{S}^{23} \mathrm{BSP}$ or with $\mathrm{P}^{2} \mathrm{CrPO}_{4}$ colloid as an internal standard to allow hepatic extraction efficiency determinations for these substances without obtaining unmixed representative hepatic vein blood samples. The two conditions underlying this use are: a) IHSA does not leave the vascular tree in amounts exceeding 1 per cent of the total injected during a single passage through the liver; this assumption has been tested and confirmed (11). b) The sole source of variable $I^{2 m}$ and $S^{25}$ or $P^{20}$ content in the blood samples must be the injected isotope mixture; this condition requires elimination of recirculation and appropriate intervals between tests to allow removal of test substances from the blood stream. Both conditions are readily met (see Results, Figure 4 ).

Analysis of samples containing the isotope mixtures is designed primarily to determine $S^{25} / I^{121}$ or $P^{20} / I^{121}$ ratios. It entails radio-assay of two aliquots for each sample, using dry planchet and end-window detector (as described above for BSP and $\mathrm{CrPO}$, assay) for one aliquot, and a wet $2 \mathrm{ml}$. sample in a well-type scintillation counter for the second. Since the ratios of response of the two detector systems are different for the $\gamma$-emitting $I^{12}$ and for each of the two $\beta$ emitters, the isotope ratio in an unknown containing the pair $\mathrm{I}^{121}-\mathrm{S}^{25}$ or $\mathrm{I}^{121}-\mathrm{P}^{20}$ can be computed from the ratio of the count rates on the two detectors for "unknown" and for the unmixed isotopes by the use of the appropriate simultaneous equations (for formula used see Appendix: a). Analysis of the solution of such a system of equations shows that the effect

2 The authors are indebted to Dr. E. L. Dobson, Donner Laboratory, University of California, Berkeley, Calif., for making available the $\mathrm{CrPO}_{4}$ radiocolloid used in this work. 
of uncertainties in count rate determination upon the calculated isotope ratio is a function of this ratio itself (see Appendix: $a$ ) as shown in Figure 1. For the system here employed the probable errors were \pm 7 per cent for $\mathrm{S}^{26} / \mathrm{I}^{131}$ and \pm 15 per cent for $\mathrm{P}^{28} / \mathrm{I}^{121}$ ratios in blood samples, and \pm 2 and \pm 4 per cent for the same ratios in the injection standards (see Appendix: $a$ ). Once these ratios are known in the appropriate blood samples and in the injection mass, the extraction efficiency, $\epsilon$, can be calculated as the fraction of test substance removed from the blood in one passage through the liver using the relations :

$$
\epsilon_{\mathrm{BSP}}=1-\frac{\mathrm{S}^{25} \mathrm{hop.v.}_{\mathrm{f}}}{\mathrm{S}_{\text {aff. bl. }}}=1-\frac{\left(\mathrm{S}^{35} / \mathrm{I}^{131}\right)_{\text {hep. v. }}}{\left(\mathrm{S}^{35} / \mathrm{I}^{131}\right)_{\text {aff. bl. }}}
$$

where hep.v. refers to representative samples of hepatic venous blood, and aff.bl. refers to the corresponding afferent blood stream. If sampling is completed before

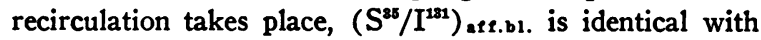

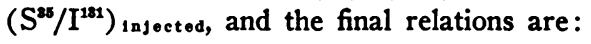

$$
\epsilon_{\mathrm{BSP}}=1-\frac{\left(\mathrm{S}^{85} / \mathrm{I}^{131}\right)_{\text {hep. v. }}}{\left(\mathrm{S}^{35} / \mathrm{I}^{131}\right)_{\text {injected }}},
$$

and a corresponding form for $\mathrm{CrPO}_{4}$.

General plan of experiments. The following in brief is the plan of experimentation to be presented.

1. Experiments were performed to ascertain whether BSP reaching the liver by way of the hepatic artery is excreted into bile at a rate different from BSP introduced into the portal vein. These include: $a$ ) single injections of $B S^{35} \mathrm{P}$ into either afferent vessel to determine whether the route of injection affects the composition or the specific activity of the complex of BSP derivatives recovered from bile; $b$ ) simultaneous injections of $S^{36}$-labeled BSP into one, and nonradioactive BSP into the other, afferent vessel followed by an appropriate period of bile collection, a second injection pair in which radioactive and nonradioactive injections are reversed and, finally, a second bile collection period.

2. Hepatic extraction efficiency for BSP delivered into either afferent vessel was determined. a) Attempts were made to accomplish this by hepatic vein catheterization. b) IHSA was used as an internal standard to allow analysis of the vena cava sample. This entails validation of the method and analysis of the catheterization artifact by the use of $\mathrm{CrPO}_{4}$ colloid as test substance and application of the method to the BSP problem.

\section{RESULTS}

\section{Single $B S^{35} P$ injections}

About $0.5 \mathrm{mg}$. per $\mathrm{Kg}$. was administered alternately into portal vein or hepatic artery of successive dogs, and bile collected in 15 minute portions until no further BSP color could be detected in two successive samples. A second injection of the same amount of $\mathrm{BS}^{35} \mathrm{P}$ was then administered into the afferent hepatic vessel not injected the first time, and another series of bile samples was collected. The general time course of BSP secretion is such that maximal dye concentrations in the bile are reached in 30 to 50 minutes; BSP concentrations fall off thereafter at such a rate that at the end of two hours no BSP color is detectable in the bile; $\mathrm{S}^{35}$ activity persists somewhat longer at a low level. As illustrated in Figure 2, the color/activity ratios for any one injection assume a constant level in the bile almost as soon as dye can be detected, and do not deviate from this value until 60 to 70 per cent of the injected $S^{35}$ has been eliminated, and color due to the dye has become all but undetectable in the bile. The $S^{35}$ excretion rate at this point has become very slow, less than 2 per cent of the peak value, and continues to decrease with a half-time of about one hour.

Table I summarizes the results of the series of successive injections. As previously observed in continuous infusion experiments (8), the ratio of $\mathrm{S}^{35} \mathrm{BSP}$ to BSP color in bile varies considerably from dog to dog but appears to be quite constant for any one dog regardless of route of administra-

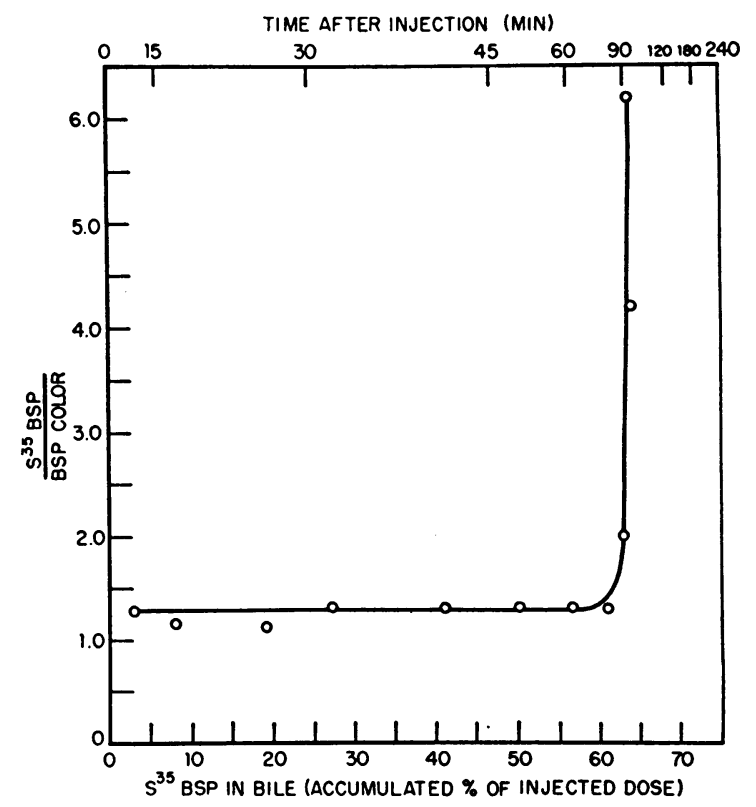

Fig. 2. Course of $\mathrm{S}^{36} \mathrm{BSP} / \mathrm{BSP}$ Color Ratio is a TYPICAL EXPERIMENT

Both the percentage of injected $S^{26}$ accumulated in bile (bottom abscissa) and the duration of bile collection (top abscissa) are indicated (Dog 56-13). 
TABLE I

Effect of route of injection on secretion of $S^{25}$ into bile

\begin{tabular}{|c|c|c|c|c|c|c|c|c|}
\hline \multirow[b]{2}{*}{$\begin{array}{l}\text { Dog } \\
\text { No. }\end{array}$} & \multirow[b]{2}{*}{$\begin{array}{l}\text { Injection } \\
\text { route } \\
\text { and } \\
\text { sequence }\end{array}$} & \multicolumn{4}{|c|}{ Peak of BSP* secretion into bile } & \multicolumn{2}{|c|}{ Total bile } & \multirow[b]{2}{*}{$\frac{\text { Ses BSP }}{\text { BSP colo }}$} \\
\hline & & $\begin{array}{l}\text { Bile } \\
\text { flow }\end{array}$ & $\begin{array}{l}\text { Sas BSP }^{\text {conc. }}\end{array}$ & $\begin{array}{c}\text { Sab BSP } \\
\text { excretion } \\
\text { rate }\end{array}$ & $\frac{\text { S56 BSP }}{\text { BSP color }}$ & $\begin{array}{l}\text { Collec- } \\
\text { tion } \\
\text { period }\end{array}$ & $\begin{array}{l}\text { Sos } \\
\text { recov- } \\
\text { ered }\end{array}$ & \\
\hline $56-12$ & $\begin{array}{l}\text { HAt } \\
\text { PV }\end{array}$ & $\begin{array}{c}\text { ml. } / \text { min. } \\
42 \\
60\end{array}$ & $\begin{array}{c}G m . / L . \\
1.13 \\
0.88\end{array}$ & $\begin{array}{c}\mu g . / \min . \\
47.4 \\
52.7\end{array}$ & $\begin{array}{l}0.97 \\
1.00\end{array}$ & $\begin{array}{l}\min . \\
320 \\
260\end{array}$ & $\begin{array}{c}\% \\
70.2 \\
67.8\end{array}$ & $\begin{array}{l}1.04 \\
1.15\end{array}$ \\
\hline $56-13$ & $\begin{array}{l}\mathrm{PV} \\
\mathrm{HA}\end{array}$ & $\begin{array}{l}53 \\
63\end{array}$ & $\begin{array}{l}0.93 \\
0.80\end{array}$ & $\begin{array}{l}49.4 \\
52.4\end{array}$ & $\begin{array}{l}1.17 \\
1.26\end{array}$ & $\begin{array}{l}230 \\
240\end{array}$ & $\begin{array}{l}79.8 \\
81.7\end{array}$ & $\begin{array}{l}1.34 \\
1.47\end{array}$ \\
\hline $56-14$ & $\begin{array}{l}\text { HA } \\
\text { PV }\end{array}$ & $\begin{array}{l}38 \\
60\end{array}$ & $\begin{array}{l}0.89 \\
1.03\end{array}$ & $\begin{array}{l}33.4 \\
61.8\end{array}$ & $\begin{array}{l}0.97 \\
1.01\end{array}$ & $\begin{array}{l}250 \\
190\end{array}$ & $\begin{array}{l}68.2 \\
69.3\end{array}$ & $\begin{array}{l}0.97 \\
1.02\end{array}$ \\
\hline $56-15$ & $\begin{array}{l}\text { PV } \\
\text { HA }\end{array}$ & $\begin{array}{l}36 \\
45\end{array}$ & $\begin{array}{l}1.15 \\
0.96\end{array}$ & $\begin{array}{l}40.5 \\
43.2\end{array}$ & $\begin{array}{l}1.13 \\
1.26\end{array}$ & $\begin{array}{l}215 \\
230\end{array}$ & $\begin{array}{l}74.6 \\
79.5\end{array}$ & $\begin{array}{l}1.27 \\
1.43\end{array}$ \\
\hline $\begin{array}{l}\text { Mean } \\
\text { values }\end{array}$ & $\begin{array}{l}\mathrm{HA} \\
\mathrm{PV}\end{array}$ & $\begin{array}{l}48 \\
50\end{array}$ & $\begin{array}{l}0.95 \\
0.99\end{array}$ & $\begin{array}{l}44.1 \\
48.3\end{array}$ & $\begin{array}{l}1.12 \\
1.10\end{array}$ & $\begin{array}{l}256 \\
253\end{array}$ & $\begin{array}{l}74.7 \\
72.3\end{array}$ & $\begin{array}{l}1.25 \\
1.22\end{array}$ \\
\hline $\begin{array}{l}\text { Mean } \\
\text { values }\end{array}$ & $\begin{array}{l}\text { 1st injection } \\
2 \text { nd injection }\end{array}$ & $\begin{array}{l}42 \\
58\end{array}$ & $\begin{array}{l}1.13 \\
0.90\end{array}$ & $\begin{array}{l}42.8 \\
50.2\end{array}$ & $\begin{array}{l}1.07 \\
1.16\end{array}$ & $\begin{array}{l}264 \\
240\end{array}$ & $\begin{array}{l}73.2 \\
74.6\end{array}$ & $\begin{array}{l}1.16 \\
1.28\end{array}$ \\
\hline
\end{tabular}

* Sulfobromophthalein sodium.

$\dagger \mathrm{HA}=$ hepatic artery; $\mathrm{PV}=$ portal vein.

tion. On averaging separately the results after intraportal BSP administration and those after intra-arterial administration, comparison shows that route of injection does not affect the $\mathrm{S}^{35} \mathrm{BSP} /$ BSP color ratios significantly, either in bile collected at the peak of BSP secretion, or in the accumulated total bile. The values are universally slightly higher for the accumulated bile samples because of the inclusion of some residual $\mathrm{S}^{35}$ excretion with little or no color equivalent. Absolute excretion rates are slightly higher for BSP injected into the portal vein than for that injected into the hepatic artery.

Differences between the group of first injections and the group of second injections are considerably larger than those between portal vein and hepatic artery injections. The rate of bile secretion itself is faster at the time of the second BSP peak than at the corresponding point after the first injection. This correlates with slightly higher rectal temperatures $\left(+0.6^{\circ} \mathrm{C}\right.$. average) and respiratory rates $(+20$ per cent average). The peak BSP secretion rate is increased less than the bile flow rate. The $\mathrm{S}^{35} \mathrm{BSP} / \mathrm{BSP}$ color ratio appears to be slightly higher-about 8 per cent average for the peak of BSP secretion, 10 per cent for the accumulated bile-for the series of second injections than for the series of first injections.

\section{Simultaneous injections}

On the basis of these results, simultaneous injection experiments to establish the relative secretion rates of identical doses of BSP delivered via hepatic artery and via portal vein must provide for determination of specific activity/color ratios for excreted $\mathrm{BS}^{35} \mathrm{P}$ for each dog and, in addition, by alternation of injection routes between dogs, allow elimination of any small effects due to the order of injections. The design adopted to meet these requirements can be represented schematically as follows:

$\begin{array}{ccll}\text { Dog } & \begin{array}{c}\text { Injection } \\ \text { pair } \\ \text { No. }\end{array} & \begin{array}{c}\text { So. } \\ \text { SoSP into }\end{array} & \begin{array}{c}\text { Nonradioactive } \\ \text { BSP into } \\ \text { pepatic artery }\end{array} \\ 1 & 1 & \text { portal vein } \\ 1 & 2 & \text { portal vein } & \text { hepatic artery } \\ 2 & 3 & \text { portal vein } & \text { hepatic artery } \\ 2 & 4 & \text { hepatic artery } & \text { portal vein }\end{array}$

This scheme is to be replicated for successive pairs of dogs. The four individual doses of BSP making up the two injection pairs given to one dog were chemically equivalent; doses ranged from 0.30 to $0.37 \mathrm{mg}$. per $\mathrm{Kg}$. for different dogs. After each first injection pair 180 minutes was allowed for completion of the dye excretion before the second injections were administered.

Figure 3 shows a typical set of results, and illustrates the method of deriving the activity/color 
ratio for one animal. The basic graph represents rate of accumulation of $S^{35}$ equivalent BSP as a function of accumulation of BSP color in the bile. In every case this plot yielded a straight line for each injection pair, with a slight upward hook near that point where BSP color excretion becomes vanishingly small while $S^{35}$ excretion still continues at a slow rate (see Figure 2). Thus, "portal vein BSP" and "hepatic artery BSP" 8 are found to be excreted in constant proportion as long as BSP color excretion continues. If this proportion were known, the activity/color ratio in bile BSP could be determined directly from the slope of the curve for each injection pair; or conversely, if the color/activity ratio were known, the excretion rate ratio could be read off in the same fashion. Actually, however, both values are unknown, and a second complementary injection pair is needed to obtain the information necessary for further calculations. In terms of BSP color, the two injection pairs do not differ, and each value

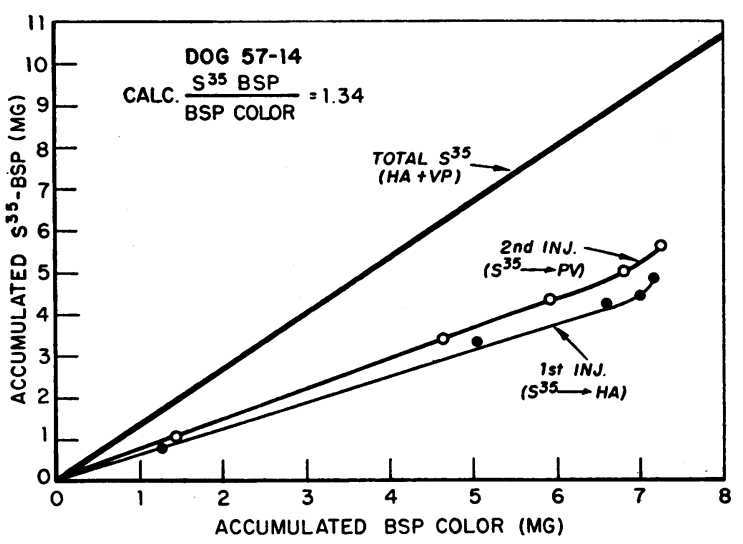

Fig. 3. Plot Used in Calculation of Characteristic $\mathrm{S}^{28} \mathrm{BSP}$ COLOR RATIO

Dog 57-14, a reciprocal paired injection experiment; see text for description.

\footnotetext{
${ }^{3}$ Actually, the distribution of "portal vein-injected BSP" in the liver is not exclusively to the hypothetical regions tributary to the portal vein because of incomplete uptake on the first passage and partial recirculation by way of the hepatic artery. A similar statement applies to "hepatic artery BSP." The actual relations can be calculated only after determination of single passage extraction efficiency (see below and Discussion). It is then found that "portal vein BSP" is actually 85 per cent portal vein and 15 per cent hepatic artery distributed and "hepatic artery BSP" is 65 per cent hepatic artery and 35 per cent portal vein distributed. With this usage restriction, however, the remainder of the argument can stand unaltered.
}

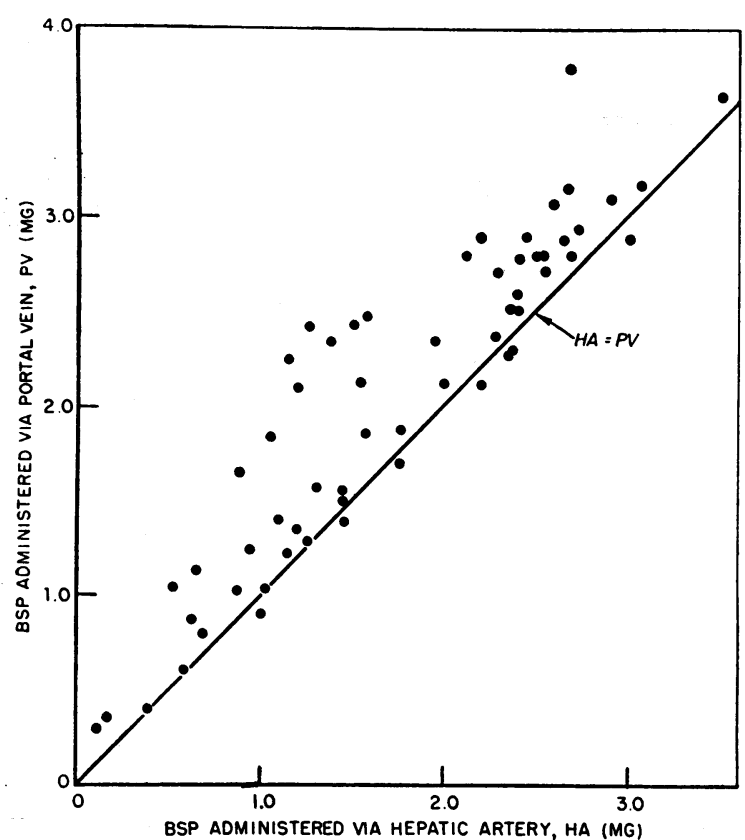

Fig. 4. Accumulation of Portal Vein-Derived BSP as a Function of Hepatic Artery-Derived BSP in Reciprocal Paired Injection Experiments

Diagonal $\mathrm{HA}=\mathrm{PV}$ represents equal secretion rates.

of accumulated bile BSP color on the abscissa of Figure 3 defines corresponding stages of BSP excretion for either injection pair.

Since, however, the $\mathrm{S}^{35} \mathrm{BSP}$ was injected first into one and then into the other afferent vessel, every number representing accumulated BSP color in the bile corresponds to two numbers, representing $\mathrm{S}^{35} \mathrm{BSP}$ accumulated in bile after intraportal and intra-arterial $\mathrm{S}^{35}$ injection, respectively. Then, adding together the two $\mathrm{S}^{35} \mathrm{BSP}$ values, corresponding to one $\mathrm{BSP}$ color value, yields the total amount of $S^{35}$ which is equivalent to the total color excreted, and the ratio of these two values is the $\mathrm{S}^{35} \mathrm{BSP} / \mathrm{BSP}$ color ratio for the particular dog under study. The only assumption entailed in this calculation is that activity/color ratios must be independent of the route of injection; this point has already been established by the results shown in Table I. Thus, the slope of the summated $\mathrm{S}^{35} \mathrm{BSP}$ line (HA + PV of Figure 3 ) is a true measure of the desired activity/color ratio.

Once this number is known for a particular dog, $\mathrm{S}^{35} \mathrm{BSP}$ concentrations in bile can be converted to $\mathrm{BSP}$ color equivalents; by subtracting these from 
the total BSP color one can calculate separately the contribution to the total bile BSP color made by each of the two injections constituting either injection pair.

The results of such calculations for a series of six dogs are presented in Table II which deals with the peak of BSP excretion, and in Figure 4 which traces the course of BSP elimination from its beginning until the rate of excretion dies away. In five out of six experiments, BSP injected into the portal vein accounted for a greater portion of the dye secreted into bile than an equivalent dose placed simultaneously in the hepatic artery; in the sixth experiment, the two doses were eliminated at substantially the same rate (Table II, last column). There is a difference between secretion
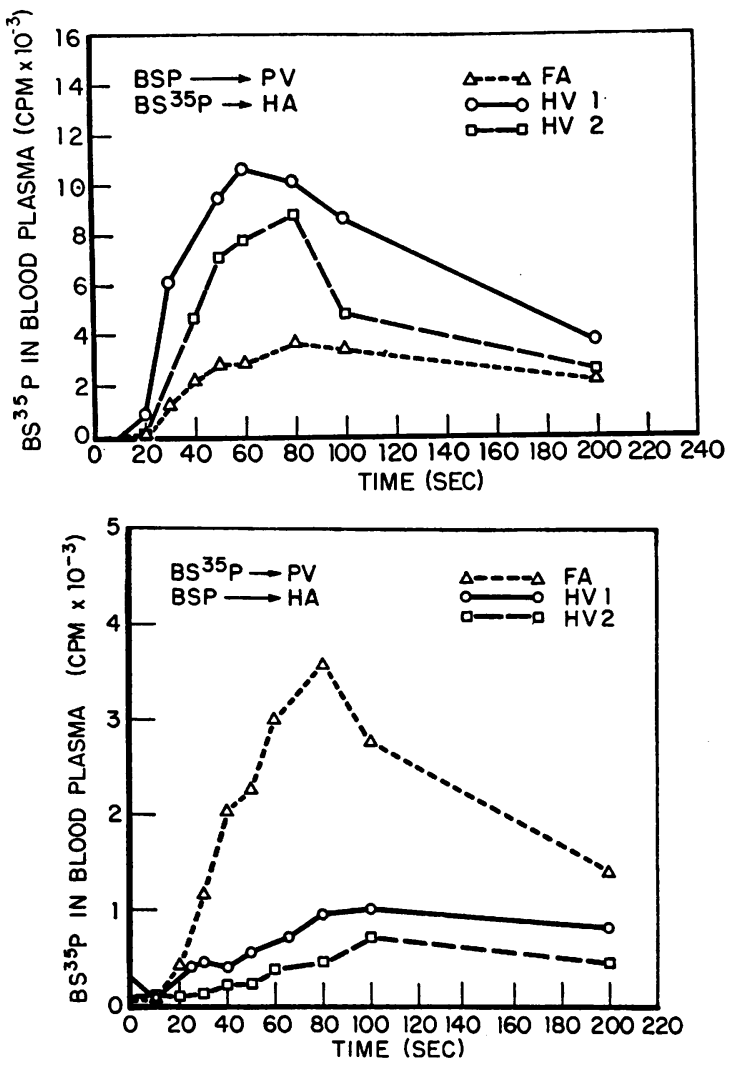

Fig. 5. Demonstration of Hepatic Vein Catheterization ARTifact

Injection routes indicated for $\mathrm{BS}^{25} \mathrm{P}$ and for $\mathrm{BSP}$; $\mathrm{HA}=$ hepatic artery, $\mathrm{PV}=$ portal vein. Ordinate represents relative $B S^{35} \mathrm{P}$ concentrations in blood from the following: $\mathrm{FA}=$ femoral artery, $\mathrm{HV}=$ hepatic vein; the numbers 1 and 2 refer to catheter locations in right and in left lateral lobes, respectively. Multipore needles used for injections. (See text). rates at the time of the first and second excretion peaks; as before, bile flow and BSP secretion rates are slightly higher at the time of the second peak. If the experiments are divided into two groups, according to whether the $\mathrm{S}^{35} \mathrm{BSP}$ was first injected into the hepatic artery or into the portal vein, it is found that the factor of order of injections does not modify the conclusions; the ratio of portal vein BSP to hepatic artery BSP in bile at the time of peak secretion is 8 per cent lower for the "artery first" group, slightly less than would be expected on the basis of the $\mathrm{S}^{35}$ $\mathrm{BSP} / \mathrm{BSP}$ color ratio differences due to injection order found in Table I. However, even where this factor would tend to give erroneously low portal vein $\mathrm{BSP} /$ hepatic artery BSP ratios, the results still favor the portal vein by almost 20 per cent (Table II, bottom section, also Appendix : b).

In Figure 4 the accumulation in bile of portal vein-injected BSP is plotted as a function of hepatic artery-injected BSP accumulation. Each injection pair is represented by four points approximately equally spaced between beginning and end of bile collection. The diagonal is the locus of points representing equality between the two routes of injection; points below this line imply preferential excretion of BSP injected into the artery, points above imply preferential excretion for BSP injected into the portal vein. The results clearly fail to indicate any special role of the hepatic artery in relation to BSP secretion; on the contrary, it appears that the portal vein distributes the dye to a region whence it is secreted somewhat more effectively than if it were distributed to the liver by way of the hepatic artery.

\section{Extraction efficiencies}

To establish whether such differences exist in dye removal from the blood as might prohibit the application of the biliary excretion results to a discussion of the postulated secretory function of the peribiliary arterial plexus, an attempt was made to estimate BSP extraction efficiencies by the use of hepatic vein catheterization. However, if rapidly collected series of blood samples were obtained not only from the hepatic vein catheters, but also from vena cava or femoral artery, results typified by Figure 5 were regularly obtained: 
TABLE II

Effect of route of injection on secretion of BSP into bile; simultaneous injection experiments

\begin{tabular}{|c|c|c|c|c|c|}
\hline $\begin{array}{c}\text { Dog No.. } \\
\text { wt. in Kg. } \\
\text { Dose: } \mu \text { g./Kg. }\end{array}$ & $\begin{array}{c}\text { Route } \\
\text { of Sob } \\
\text { injected }\end{array}$ & $\begin{array}{l}\text { Bile } \\
\text { flow } \\
\text { rate }\end{array}$ & $\begin{array}{l}\text { BSP from } \\
\text { hepatic } \\
\text { artery }\end{array}$ & $\begin{array}{c}\text { BSP from } \\
\text { portal } \\
\text { vein }\end{array}$ & $\begin{array}{c}\text { Portal vein } \\
\text { Hepatic artery BSP }\end{array}$ \\
\hline \multirow{2}{*}{$\begin{array}{c}56-3 \\
12.0 \\
0.33\end{array}$} & PV & $\begin{array}{l}\mu l . / m i n . \\
80\end{array}$ & $\begin{array}{c}\mu \mathrm{g} . / \mathrm{min} . \\
55.0\end{array}$ & $\begin{array}{c}\mu \mathrm{gg} / \mathrm{min} . \\
60.5\end{array}$ & 1.1 \\
\hline & $\mathrm{HA}$ & 120 & 76.4 & 93.0 & 1.3 \\
\hline \multirow{2}{*}{$\begin{array}{c}56-4 \\
9.1 \\
0.33\end{array}$} & $\mathrm{HA}$ & 60 & 22.2 & 44.5 & 2.0 \\
\hline & PV & 110 & 31.8 & 58.3 & 1.7 \\
\hline \multirow{2}{*}{$\begin{array}{c}56-11 \\
10.2 \\
0.37\end{array}$} & PV & 80 & 51.2 & 67.0 & 1.4 \\
\hline & HA & 110 & 70.4 & 82.5 & 1.2 \\
\hline \multirow{2}{*}{$\begin{array}{c}56-14 \\
12.8 \\
0.30\end{array}$} & HA & 90 & 30.5 & 32.2 & 1.1 \\
\hline & PV & 140 & 46.0 & 50.2 & 1.1 \\
\hline \multirow{2}{*}{$\begin{array}{c}56-15 \\
12.5 \\
0.34\end{array}$} & PV & 140 & 117.0 & 120.0 & 1.0 \\
\hline & HA & 130 & 96.0 & 89.5 & 0.94 \\
\hline \multirow{2}{*}{$\begin{array}{c}58-1 \\
10.0 \\
0.33\end{array}$} & $\mathrm{HA}$ & 180 & 44.2 & 46.5 & 1.1 \\
\hline & PV & 160 & 39.2 & 46.3 & 1.2 \\
\hline \multirow{2}{*}{$\begin{array}{c}\text { Mean } \\
23.8 \\
0.33\end{array}$} & 1st injection & 105 & 53.3 & 61.7 & 1.3 \\
\hline & 2nd injection & 129 & 60.9 & 70.0 & 1.2 \\
\hline $\begin{array}{l}\text { Mean } \\
23.3 \\
0.34\end{array}$ & $\begin{array}{c}\text { "Artery first" } \\
\text { dose }\end{array}$ & 123 & 35.7 & 46.3 & 1.3 \\
\hline $\begin{array}{l}\text { Mean } \\
24.3 \\
0.32\end{array}$ & $\begin{array}{l}\text { "Portal vein } \\
\text { first" dose }\end{array}$ & 110 & 77.7 & 85.4 & 1.2 \\
\hline
\end{tabular}

if the $\mathrm{S}^{35}$-labeled dye had been injected into the hepatic artery, one obtained the expected pattern in which the hepatic vein samples showed the earliest appearance of the dye and the highest BSP concentrations (Figure 5A). If the site of injection had been the portal vein, the hepatic vein catheter samples did not show high $B S P$ concentrations until after the peripheral circulation samples, and even then hepatic vein BSP concentrations were less than peripheral ones, in a manner which would be expected if the BSP had reached the liver only by way of the peripheral circulation in the first place (Figure 5B).

This peculiar failure of the hepatic vein catheters to "see" portal vein injected BSP could be due either to a large portacaval bypass-unlikely in the normal dog-or to a circulatory adjustment within the liver, shunting blood away from the zone sampled by an intravenous catheter. A third possibility, ascribing the effect to streamlined flow in the portal vein, was rendered highly improbable by two observations: $a$ ) if instead of the open ended needle, a sealed needle with multiple minute lateral holes were used for injection, the injection mass entered the portal vein in the form of minute jets at right angles to the line of flow, so that distribution throughout the portal blood stream should at the least have been much improved; yet the analytical results obtained by this procedure did not differ from those described for the open needle injections. $b$ ) Seven experiments were carried out in which two catheters were introduced into hepatic veins of lobes to the right and to the left of the Cantlie-Sérégé plane, in addition to placing sampling catheters in the vena cava just above the diaphragm, and in the femoral artery. A total of nine injections of $S^{35}$ $\mathrm{BSP}$, and three injections of T1824 were adminis- 
tered by the intraportal route in these animals. In every case the peak concentrations of dye attained in both hepatic veins were substanially lower than those found in the vena cava or femoral artery samples in the manner shown in Figure 5B; the time of appearance of the dyes in the several sites also differed significantly, the hepatic vein sample series being delayed by about 15 seconds relative to the femoral artery samples, and by about 24 seconds relative to the vena cava sample series. Similar anomalies were not observed with hepatic artery injections. It would have to be a rather extraordinary coincidence if in every one of these experiments streamlining of portal flow would be such as to bypass two sampling sites in the two liver moieties, unless one accepts (as we do) the conclusion that the presence of a catheter in the hepatic vein tends to minimize portal flow through the tissue elements in the immediate vicinity of the catheter tip.

To obviate these sampling difficulties, IHSA was used as an internal standard so that, prior to recirculation, vena cava blood samples could be used for determination of the fraction of BSP removed from blood in one passage through the liver by the application of the analytical and computational methods described (see Methods, and Appendix: $a$ ). A typical experiment is illustrated by Figure 6: a mixture of IHSA and test

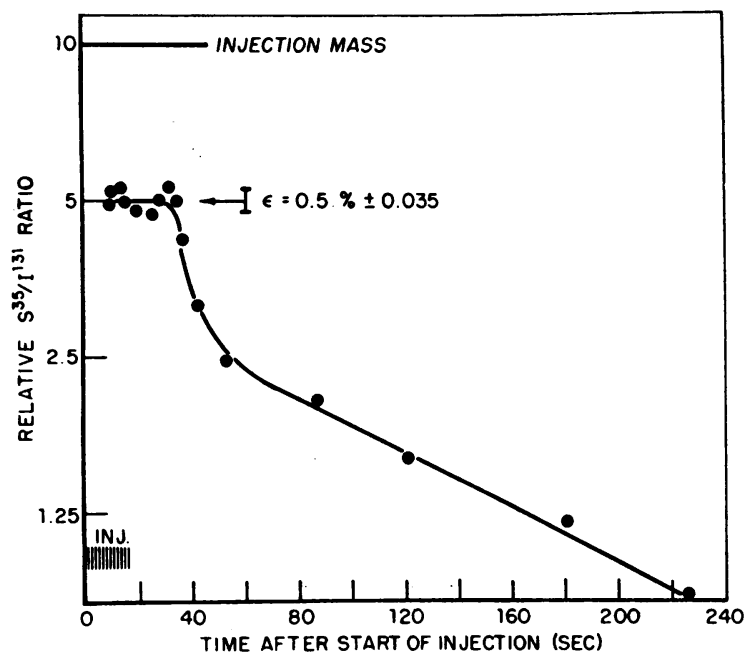

Fig. 6. Internal Tracer Method

Graph used in calculation of extraction efficiency for BSP for portal vein-injected $\mathrm{BS}^{25} \mathrm{P}$ in Dog 57-25; see text for description.
TABLE III

Effect of route of injection on extraction of $\mathrm{Cr}_{\mathrm{PO}}$ from blood in one passage through the liver

\begin{tabular}{ccc}
\hline \hline Dog & $\begin{array}{c}\text { Route of } \\
\text { injection }\end{array}$ & $\begin{array}{c}\text { CrPO, extracted } \\
\text { in one passage }\end{array}$ \\
\hline No. & & $\%$ \\
$57-4$ & HA & 81.6 \\
& PV & 88.2 \\
& PV & 76.4 \\
$57-6$ & HA & 89.1 \\
& PV & 52.7 \\
$57-8$ & HA & 57.4 \\
& HA & 90.4 \\
& PV & 78.8 \\
$57-9$ & PV & 83.3 \\
& HA & 73.0 \\
& PV & 68.0 \\
& HA & 79.2 \\
Mean values & PV & 78.5 \\
& PV & $78.5 \pm 13.1$ \\
& HA & $75.5 \pm 11.2$ \\
\hline
\end{tabular}

substance ( $\mathrm{S}^{35} \mathrm{BSP}$ in this case) is injected into the vessel chosen for study at an approximately constant rate over 15 seconds, Beginning at the same time as the injection, multiple sequential blood samples are drawn from the inferior vena cava just above the diaphragm, and are analyzed as described in Methods. The results, expressed as $S^{35} / \mathrm{I}^{131}$ ratios, are plotted in Figure 6.

The blood carrying the injected tracer mixture begins to arrive at the venous catheter six to eight seconds after the start of the injection. $\mathrm{S}^{\mathbf{3 5}} / \mathrm{I}^{\mathbf{1 3 1}}$ ratios remain substantially constant from this point on until blood begins to arrive which has recirculated once more through the liver. This point is marked by a sharp decrease of $S^{35} / I^{131}$ ratios which thenceforth continue to decrease in an approximately exponential fashion. The $S^{35} / I^{131}$ ratio during the single passage plateau period is the value from which extraction efficiency of the liver for the test substance-BSP in this caseis calculated by comparison with the corresponding ratio in the injection mass.

Table III presents the results of a series of determinations, by this procedure, of $\mathrm{CrPO}_{4}$ colloid extraction efficiency as a function of the route of injection. Although extraction efficiencies in general fall into the range of 70 to 90 per cent, it may be noted that an occasional dog may show consistently lower extraction efficiencies. The 
TABLE IV

Effect of route of injection on extraction of BSP from blood in one passage through the liver

\begin{tabular}{ccc}
\hline \hline Dog & $\begin{array}{c}\text { Route of } \\
\text { injection }\end{array}$ & $\begin{array}{c}\text { Sas extracted } \\
\text { in one passage } \\
\text { through the liver }\end{array}$ \\
\hline No. & HA & $\%$ \\
$57-16$ & PV & 58 \\
$57-22$ & PV & 63 \\
& HA & 71 \\
$57-24$ & PV & 46 \\
& HA & 49 \\
$57-25$ & PV & 46 \\
& HA & 46 \\
$57-26$ & PV & 50 \\
& PV & 36 \\
& HA & 36 \\
Mean values & PV & 35 \\
& HA & $52.0 \pm 8.1$ \\
& PV & $47.2 \pm 4.2$ \\
\hline
\end{tabular}

route of $\mathrm{CrPO}_{4}$ administration does not affect the efficiency with which this substance is removed from the blood stream in passage to the vena cava. Hence it may be concluded that a major vascular bypass between portal vein and vena cava or systemic circulation did not exist in these dogs.

The results of a series of measurements of BSP extraction efficiency are contained in Table IV. In three out of five dogs the hepatic arterial route of injection led to slightly higher efficiency of BSP extraction than the portal venous route; in one dog the reverse was seen; no differences were found in the fifth animal. These studies, therefore, lend some support to previous work indicating slightly greater BSP extraction from hepatic arterial blood (6). The difference is hardly significant, however, $(p>0.1)$, and in its application to the biliary secretion data would serve only to reinforce the conclusion that BSP, taken up by the those regions of the liver supplied with hepatic arterial blood primarily, is not excreted in preference to portal vein-distributed BSP.

\section{DISCUSSION}

In recent years, several problems connected with the functional anatomy of the liver have been revived by workers attempting to reconcile the results of morphologic and of physiologic experimentation. One of these problems has been raised by the description of the extensive vascular and lymphatic plexus enmeshing the bile ducts (1-3). The functional significance of this structure has given rise to a good deal of speculation concerning the possible secretory importance of the smaller bile ducts $(12,13)$. Since this plexus is supplied by the hepatic artery and represents the only vascular element not traversed to an equal extent by blood from portal vein and from hepatic artery, experimental approaches have dwelt on differences in the handling of substances reaching the liver by one or the other of these vascular routes.

BSP in particular has been examined from this point of view, and differences have been described in the persistence of the ability of the liver to remove this substance from the two afferent blood streams, the hepatic arterial route presumably showing satisfactory extraction for longer periods of time than the portal route (6). Unfortunately, at the time of these experiments it had not yet been recognized that BSP is not excreted as such in the bile (14) and that after prolonged BSP infusions the proportion of BSP proper in the blood stream is actually quite small $(15,16)$. Differences in BSP handling under these conditions are not readily interpretable, especially since it is clear that what ever other functions it may subserve, the peribiliary vascular plexus must be the site where considerable diffusional exchange between blood and bile constituents takes place (17).

In testing the thesis that an excretory function is served by the peribiliary arterial plexus, therefore, it now appeared essential to design experiments that would provide direct intercomparison of the actual rate of secretion into bile of BSP taken up as such from either the hepatic artery or the portal vein. This design, embodying bile analyses of necessity, has the further advantage that the high degree of concentration of BSP in the bile allows the use of such small doses of the dye that quite high extraction efficiencies-and consequently. quite selective distribution along the vascular pathway-could be anticipated.

In applying isotopically-labeled BSP to such experiments as a tracer for one of two simultaneous streams of dye, its conversion to a whole family of optically indistinguishable dyes of varying color to radioactivity ratios poses a special problem (8). It was demonstrated in the present series of 
experiments that the route of injection does not measurably affect this ratio, so that no bias is introduced into the analyses from this source. A possible small difference between successive injections in the same animal was recognized but could be eliminated by proper alternation of injection routes.

On this basis the key experiment of the present series is that represented by Table II and Figure 4, comparing the rates of secretion into bile of equal doses of BSP simultaneously reaching the liver of the same animal by way of either portal vein or hepatic artery. The experimental results do not under any circumstances admit of the interpretation that BSP injected into the hepatic artery is preferentially excreted. There is an indication, on the contrary, that the portal venous route affords a small but quite consistent advantageBSP injected by this route being eliminated about 15 to 20 per cent faster at the time of peak BSP elimination.

The significance of this observation for the assessment of the functional role of the hepatic artery depends upon the additional information presented in Table IV concerning hepatic extraction efficiencies for BSP. The fact that these are either route independent, or that the hepatic arterial flow is somewhat more completely cleared of $\mathrm{BSP}$ - this in line with previous observations (6) - justified the conclusion that the vascular region supplied by the hepatic artery is not peculiarly active in transferring BSP from blood to bile. This would appear to remove any present justification from the postulate that the structures supplied by the peribiliary plexus (notably the smaller bile ducts) are endowed with any specific functional importance with regard to bile secretion. The present evidence does not, of course, bear upon a possible role of the structures in this region in the resorption of various components from bile in progress through the biliary tree.

Knowledge of the first passage extraction efficiencies for BSP allows an estimate of the actual distribution of BSP among vascular regions, provided one can estimate the relative blood flow rates through the two major vessels. A reasonable (and conservative) relation applicable to the present conditions would appear to be somewhere between $1 / 3$ and $1 / 5$ for the ratio hepatic arterial/ portal venous flow (18-22); together with an initial extraction efficiency of 50 per cent this would lead to eventual distribution of BSP between the two vascular regions of $85 / 15$ for the case of intraportal, and 35/65 for the case of intra-arterial injection. Thus, distribution differences would appear large enough to reveal any real differences in excretory activity.

There is not, at present, any explanation for the faster excretion into bile of portal vein-carried BSP suggested by Table II and Figure 4 . One would be inclined to seek for explanations either in differences in mean oxygen tensions obtaining in regions receiving blood from the one or the other source, or in peculiarities of the sinusoidal circulation. An attempt was made to test this alternative by carrying out experiments analogous to the ones here reported under total oxygen tensions of 3.4 atmospheres resulting in "arterialization" of all circulating blood. The results suggested that oxygenation does not affect the excretory relations depicted in Figure 4; interpretation of these experiments, however, is rendered less than satisfactory by simultaneously occurring changes in respiratory movements and in rectal temperatures, both of which may have a bearing on bile flow and bile secretion.

Finally, attention may be called briefly to the results epitomized by Figure 5 and Table IV confirming in dogs under the experimental conditions of the present series the existence of a catheterization artifact as reported by Sapirstein and Reininger (23), and lending support to their general interpretation of the nature of this phenomenon. The present authors feel that a special reflex vasoconstriction is not required for interpretation of these observations but that the plasticity of blood flow distribution in the sinusoidal bed alone suffices to account for the deflection of portal flow away from a catheterized region. If borne out, this interpretation would assign to the hepatic arterial circulation a new role as an emergency supply to regions of the hepatic parenchyma, the circulation of which has been mildly compromised. Such a role could become of prime importance in the early stages of the development of liver injury by preventing the establishment of the vicious circle of liver disease envisioned by Himsworth (24). 
As applied to hepatic vein sampling, the present results suggest that even if one encounters a catheterization artifact, in the normal liver at least, this is not important in $\mathrm{BSP}$ or $\mathrm{CrPO}_{4}$ studies unless one specifically desires to discriminate between hepatic artery and portal vein as injection routes. Thus, if the test substances are injected into the peripheral circulation of such animals in such a way that they reach portal vein and hepatic artery in the same concentrations, the lack of difference between the efficiency of $\mathrm{BSP}$ or $\mathrm{CrPO}_{4}$ removal from either blood stream implies that hepatic catheterization ought to yield meaningful results.

In the present case, of course, these assumptions could not be made a priori but, on the contrary, their verification was the object of the experiments. The use of an internal standard which allows sampling vena cava blood above the liver, in lieu of hepatic vein blood, was shown to obviate these difficulties and appears to be satisfactory for wider application whenever plasma protein flux across the hepatic tree is not excessive. It might be mentioned in passing that the limitations of this procedure are such that clear discrimination of first passage and recirculation phases becomes difficult unless samples are drawn close to the point of admixture of hepatic vein and vena cava blood streams.

The series of experiments here reported then, leads to the following conclusions. 1) A special role of the peribiliary arterial plexus in the secretion of BSP into bile could not be demonstrated. It is suggested instead that this plexus and its adjacent structures contribute to the modification of bile composition by exchange of certain constituents among bile, lymph, and blood. 2) Catheterization of the hepatic veins in the dog in these experiments led to changes in blood flow distribution which resulted in an excessive proportion of hepatic artery-derived blood in the catheter samples. It is suggested that this phenomenon may point to a hitherto unrecognized role of the hepatic artery as a safeguard against transient regional ischemia in the liver under mechanical stress. In its application to hepatic vein sampling this effect is not critical unless one desires to discriminate between the fate of a constituent reaching the liver by way of either the hepatic arterial or the portal venous blood stream. 3) A method has been designed for overcoming this difficulty by the use of an internal standard in studies of extraction efficiency of test substances like $\mathrm{CrPO}_{4}$ colloid, or BSP. 4) Results of such measurements show no route-dependent differences in $\mathrm{CrPO}_{4}$ extraction, and a (questionably) somewhat more complete extraction of BSP from the hepatic arterial stream.

\section{SUMMARY}

Differences in the handling of sulfobromophthalein sodium (BSP) reaching the liver have been claimed previously, depending upon whether administration was by way of the portal vein or the hepatic artery. This question has been investigated using $\mathrm{S}^{35}$-labeled $\mathrm{BSP}$ to trace one of two equal simultaneous BSP doses (to hepatic artery and to portal vein) from injection site into the bile. The conditions under which such experiments can be interpreted have been elucidated. The results obtained indicate that route-determined differences in BSP secretion are either nonexistent or favor BSP reaching the liver in the portal venous blood stream.

The efficiency of BSP removal from portal vein and from hepatic artery blood has been studied using radioiodinated serum albumin as an internal standard to obviate the impossibility of obtaining representative hepatic vein blood samples by catheterization. BSP is extracted with an efficiency of 52 per cent from hepatic artery blood and 47 per cent from portal vein blood. From these two sets of results it is concluded that the hepatic artery, the peribiliary arterial plexus which it supplies, and the bile ducts enmeshed by this plexus do not play any special role in BSP secretion into bile.

In connection with the extraction efficiency studies, it was shown that blood samples from hepatic vein catheters contain an excessive proportion of blood originally supplied by the hepatic artery and that this is a genuine catheter artifact rather than the result of porta systemic shunts or of streamlined portal flow.

\section{APPENDIX}

a. Calculations bearing on the derivation of extraction efficiencies from double isotope injections incorporating an 
internal standard. The general equations applicable to these calculations are:

1) $\frac{A}{B}=\frac{\beta_{2} C_{1}-\beta_{1} C_{2}}{\alpha_{1} C_{2}-\alpha_{2} C_{1}}$ for the isotope ratio,

and

2) $\frac{\Delta(\mathrm{A} / \mathrm{B})}{\mathrm{A} / \mathrm{B}}=\left(\mathrm{K}_{\mathrm{I}} \frac{\mathrm{A}}{\mathrm{B}}+\mathrm{K}_{\mathrm{II}}+\mathrm{K}_{\mathrm{III}} \frac{\mathrm{B}}{\mathrm{A}}\right) \cdot \delta$ for the calculation of relative probable error in the isotope ratio. Here $\mathrm{A}$ and $\mathrm{B}$ are the relative amounts of isotopes $\mathrm{A}$ and $\mathrm{B}$ in arbitrarily chosen units (which, however, once chosen determine the numerical values of the remaining constants and of the results); numbers 1 and 2 refer to the two detectors employed, $\alpha_{1}$ and $\beta_{1}$, and $\alpha_{2}$ and $\beta_{2}$ are the count rates of one unit of pure $A$ or pure $B$ when placed under detector 1 or 2 , and $C_{1}$ and $C_{2}$ are the count rates actually recorded for the experimental sample under detectors 1 and 2. $\Delta(\mathrm{A} / \mathrm{B})$ is the error in $\mathrm{A} / \mathrm{B}$ calculated to result from errors of $\pm 100 \delta$ per cent in the determination of both $\mathrm{C}_{1}$ and $\mathrm{C}_{2} ; \mathrm{K}_{\mathrm{I}}, \mathrm{K}_{\mathrm{II}}$ and $\mathrm{K}_{\mathrm{III}}$ are constants derived from appropriate manipulation of Equation 1:

$$
\begin{aligned}
\mathrm{K}_{\mathrm{I}} & =\frac{1.41 \cdot \alpha_{1} \alpha_{2}}{\alpha_{1} \beta_{2}-\alpha_{2} \beta_{1}} \\
\mathrm{~K}_{\mathrm{II}} & =\frac{1.41\left(\alpha_{1} \beta_{2}+\alpha_{2} \beta_{1}\right)}{\alpha_{1} \beta_{2}-\alpha_{2} \beta_{1}} \\
\mathrm{~K}_{\mathrm{III}} & =\frac{1.41 \cdot \beta_{1} \beta_{2}}{\alpha_{1} \beta_{2}-\alpha_{2} \beta_{1}} .
\end{aligned}
$$

Using as a unit of isotope an amount giving $1,000 \mathrm{cpm}$ in a specified geometry on the end-window detector, the following are the numerical equations for the case of $\mathrm{I}^{131}=\mathrm{A}$ and $\mathrm{S}^{35}=\mathrm{B}$ and, for the detectors employed by the authors ( 1 referring to the scintillation detector, 2 to the end-window counter)

and

$$
\frac{I^{131}}{S^{35}}=\frac{C_{1}-1.41 \times 10^{-2} C_{2}}{3.70 C_{2}-C_{1}}
$$

$$
\frac{\Delta\left(\mathrm{I}^{131} / \mathrm{S}^{35}\right)}{\mathrm{I}^{131} / \mathrm{S}^{35}}= \pm\left(4.17 \frac{\mathrm{I}^{131}}{\mathrm{~S}^{35}}+4.17+0.017 \frac{\mathrm{S}^{35}}{\mathrm{I}^{131}}\right) \cdot 10^{-2}
$$

where $100 \delta= \pm 3$ per cent and it is assumed that the constants $\alpha_{1}$ etc. are determined to within \pm 1 per cent or better. The relation between I/S and the probable error is graphically represented in Figure 1. In practice, isotope mixtures for injection were prepared so as to give an initial $\mathrm{I}^{131} / \mathrm{S}^{35}$ around 0.125 ; experience showed that in one passage through the liver this ratio was displaced to the left by an amount indicated approximately by the interval shown above the graph, corresponding to a BSP extraction efficiency of 50 per cent. The values for $\mathrm{I}^{131} / \mathrm{S}^{35}$, consequently, are reliable to \pm 7 per cent or better throughout, provided the calculations are based on individual count rates reliable to \pm 3 per cent as used for the blood samples. Injection standards were counted to $100 \delta= \pm 1$ per cent. Similar relations hold for $\mathrm{CrPO}_{4}$, but relative error here is \pm 15 per cent for counting accuracy of \pm 3 per cent.

b. Expressing all BSP values as "colorimetric BSP" (so that $\mathrm{S}^{35} \mathrm{BSP}$ values are multiplied by the mean BSP color/ activity ratio for the biliary BSP complex in the particular dog, yielding amounts of BSP or BSP complex equivalent colorimetrically to the recovered $S^{35}$ ), the ratio of arteryinjected/portal vein-injected BSP is calculated from the following relations:

$$
\begin{aligned}
& A=C-S \frac{\bar{C}}{\bar{S}} \\
& V=S \frac{\bar{C}}{\bar{S}}
\end{aligned}
$$

and

$$
\frac{V}{A}=\frac{S \frac{\bar{C}}{\bar{S}}}{C-S \frac{\bar{C}}{\bar{S}}}
$$

for the bile recovered after an injection pair in which the $\mathrm{S}^{35}$ went into the portal vein; and

$$
\begin{aligned}
& \mathrm{A}^{\prime}=\mathrm{S}^{\prime} \frac{\overline{\overline{\mathrm{C}}}}{\mathrm{V}^{\prime}}=\mathrm{C}^{\prime}-\mathrm{S}^{\prime} \frac{\overline{\overline{\mathrm{C}}}}{\overline{\mathrm{S}}} \\
& \frac{\mathrm{V}^{\prime}}{\mathrm{A}^{\prime}}=\frac{\mathrm{C}^{\prime}-\mathrm{S}^{\prime} \frac{\overline{\overline{\mathrm{C}}}}{\mathrm{S}^{\prime} \frac{\overline{\mathrm{S}}}{\overline{\mathrm{S}}}}}{}
\end{aligned}
$$

for an injection pair involving $\mathrm{S}^{35} \mathrm{BSP}$ injection into the hepatic artery. In these equations $\mathrm{A}$ and $\mathrm{V}, \mathrm{A}^{\prime}$ and $\mathrm{V}^{\prime}$ are artery and vein-derived BSP after first and second injections; $\mathrm{S}$ and $\mathrm{C}$, and $\mathrm{S}^{\prime}$ and $\mathrm{C}^{\prime}$ are corresponding $\mathrm{S}^{35} \mathrm{BSP}$ and BSP color concentrations after first and second injections; and $\overline{\mathrm{S}}$ and $\overline{\mathrm{C}}$ are the cumulative $\mathrm{S}^{35} \mathrm{BSP}$ and BSP color amounts (see Figure 3 ) from which the color/activity ratio is calculated. If the order of injections were as represented by the sequence of equations here, one would be dealing with a "portal vein first" experiment in the sense of Table II. The sequence effect illustrated at the bottom of Table I would lead to the prediction that $\mathrm{S}^{\prime}$ would be too large (relative to $S$ ) by about 10 per cent, and $\bar{S}$ would therefore be too large by about $\frac{10}{2}$ or 5 per cent. Examination of the equations for $\frac{V}{A}$ and $\frac{V^{\prime}}{A^{\prime}}$ shows that in this case both calculated ratios should be smaller than they would be in the absence of a sequence effect, and would deviate from the "correct" value by about the same amount (in the present example, provided $\mathrm{A}$ is not too different from $V$, and $\bar{S}$ from $\frac{\bar{C}}{2}$, the error would amount to about 10 per cent). By the same reasoning in "artery first" experiments the calculated values for $\frac{V}{A}$ and $\frac{V^{\prime}}{A^{\prime}}$ would be increased as a result of the injection sequence effect. As seen in Table II, the observed direction of the discrepancies between "portal vein first" and "artery first" experiments is as predicted, although the observed spread of mean values is somewhat smaller than would follow from these calculations. 


\section{REFERENCES}

1. Andrews, W. H. H., Maegraith, G. G., and Wenyon, C. E. M. Studies on liver circulation; microanatomy of hepatic circulation. Ann. trop. Med. Parasit. 1949, 43, 229.

2. Julian, L. M., and DeOme, K. B. Studies on the subgross anatomy of the bovine liver. I. The distribution of the blood vessels and bile ducts as revealed by the vinylite-corrosion technique. Amer. J. vet. Res. 1949, 10, 331.

3. Deakins, J. S., and Sugiura, H. Circulatory and bile duct systems in rodent livers (abstract). Anat. Rec. 1949, 103, 569.

4. Andrews, W. H. H. Excretory function of the liver; a reassessment. Lancet 1955, 269, 166.

5. Andrews, W. H. H. Bile duct cells and bile secretion in Liver Function, R. W. Brauer, Ed. Amer. Inst. Biol. Sci. 1958, Publication No. 4, p. 241.

6. Andrews, W. H. H., Maegraith, B. G., and Richards, T. G. The effect upon bromsulphalein extraction of the rate and distribution of blood flow in the perfused canine liver. J. Physiol. (Lond.) 1956, 131, 669.

7. Krebs, J. S., and Brauer, R. W. The Synthesis of Sulfobromophthalein Sodium containing $S^{35}$. U. S. Naval Radiological Defense Lab. Technical Report, 1955, No. 67.

8. Brauer, R. W., Pessotti, R. L., and Krebs, J. S. The distribution and excretion of $\mathrm{S}^{25}$-labeled sulfobromophthalein-sodium administered to dogs by continuous infusion. J. clin. Invest. 1955, 34, 35.

9. Dobson, E. L., and Jones, H. G. The behavior of intravenously injected particulate material. Its rate of disappearance from the blood stream as a measure of liver blood flow. Acta med. scand. 1951, 144, suppl. 273.

10. Brauer, R. W., Leong, G. F., McElroy, R. F., and Holloway, R. J. Circulatory pathways in the rat liver as revealed by $\mathrm{P}^{32}$ chromic phosphate colloid uptake in the isolated perfused liver preparation. Amer. J. Physiol. 1956, 184, 593.
11. Holloway, R. J., Leong, G. F., and Brauer, R. W. To be published.

12. Wilson, J. W. Hepatic structure in relation to function in Liver Function, R. W. Brauer, Ed. Amer. Inst. Biol. Sci. 1958, Publication No. 4, p. 175.

13. Maegraith, B. G. Bile duct cells and their blood supply in Liver Function, R. W. Brauer, Ed. Amer. Inst. Biol. Sci. 1958, Publication No. 4, p. 235.

14. Krebs, J. S., and Brauer, R. W. Metabolism of sulfobromophthalein sodium (BSP) in the rat. Amer. J. Physiol. 1958, 194, 37.

15. Krebs, J. S. The relation of the metabolism of sulfobromophthalein sodium to its blood clearance in the rat. Amer. J. Physiol. In press.

16. Meltzer, J. I., Wheeler, H. O., and Cranston, W. I. Metabolism of sulfobromophthalein sodium (BSP) in dog and man. Proc. Soc. exp. Biol. (N. Y.) 1959, 100, 174.

17. Brauer, R. W. Mechanisms of bile secretion. J. Amer. med. Ass. 1959, 169, 1462.

18. Grab, W., Janssen, S., and Rein, H. Die Leber als Blutdepot. Klin. Wschr. 1929, 8, 1539.

19. Schwiegk, H. Untersuchungen über die Leberdurchblutung und den Pfortaderkreislauf. NaunynSchmiedeberg's Arch. exp. Path. Pharmak. 1932, 168, 693.

20. Soskin, S., Essex, H. E., Herrick, J. F., and Mann, F. C. The mechanism of regulation of the blood sugar by the liver. Amer. J. Physiol. 1938, 124, 558.

21. McMichael, J. The oxygen supply of the liver. Quart. J. exp. Physiol. 1937/38, 27, 73.

22. Myers, J. D. The hepatic blood flow in Laennec's cirrhosis, with an estimate of the relative contributions from portal vein and hepatic artery (abstract). J. clin. Invest. 1950, 29, 836.

23. Sapirstein, L. A., and Reininger, E. J. Catheter induced error in hepatic venous sampling. Circulat. Res. 1956, 4, 493.

24. Himsworth, H. P. Lectures on the Liver and Its Diseases. Cambridge, Mass., Harvard Univ. Press, 1947, p. 43. 